\title{
DESKRIPSI VARIAN PERMAINAN TRADISIONAL DAERAH NUSA TENGGARA BARAT
}

\author{
Ashar Pajarungi Anar ${ }^{1, *}$, Nurul Kemala Dewi ${ }^{2)}$, Mohammad Archi Maulyda ${ }^{3)}$ \& Nursaptini ${ }^{4)}$ \\ 1), 2), 3), 4) Universitas Mataram, Mataram, Indonesia \\ E-mail: ashar.pajarungianar@unram.ac.id
}

\begin{tabular}{|c|c|}
\hline ARTICLE INFO & ABSTRACT \\
\hline $\begin{array}{l}\text { Article history } \\
\text { Received: August 18, } 2020 \\
\text { Revised: August 22, } 2020 \\
\text { Accepted: August 24, } 2020 \\
\text { Keywords: } \\
\text { traditional games, children, } \\
\text { west nusa tenggara }\end{array}$ & $\begin{array}{l}\text { We can find various types of electronic devices that are so sophisticated } \\
\text { followed by the emergence of various types of modern games or online games } \\
\text { that can be so easily accessed by children. So that at this time traditional } \\
\text { games are becoming obsolete and modern or online games are preferred. The } \\
\text { type of research used is descriptive qualitative research and data collection } \\
\text { techniques carried out by observation, interviews and documentation. The } \\
\text { traditional games originating from the province of West Nusa Tenggar, } \\
\text { namely, the first traditional games originating from Lombok such as } \\
\text { Lunglungse Games, Manuk Kurung Games, Jumpring Games, Shopping } \\
\text { Games, and Game Peresean. The Sumbawa Traditional Games are Logok } \\
\text { Game, Rabanga Game, Kebo Play Game, and Karaci Game. The Bima } \\
\text { Dompu Traditional Games are Mpaa Sila Games, Baleba Games, and Parise } \\
\text { Games. The benefits of knowing the types of traditional games so that } \\
\text { Indonesian people especially the people of West Nusa Tenggara province can } \\
\text { add more insight and are expected to be preserved so that thevare not extinct. }\end{array}$ \\
\hline
\end{tabular}

\section{A. PENDAHULUAN}

Negara Indonesia merupakan Negara yang kaya akan budaya, tradisi, bahkan berbagai macam permainan tradisional. Dibeberapa daerah tidak jarang ditemukan jenis permainan yang sama, meskipun namanya berbeda. Permainan tradisional adalah warisan kekayaan yang perlu dilestarikan. Terlebih lagi aneka permainan tradisional mengandung nilai-nilai positive bagi kehidupan anak.

Menurut Soepandi, 1986 (dalam Khasanah, 2013) Permainan yaitu perbuatan untuk menghibur hati baik yang mempergunakan alat ataupun tidak menggunakan alat. Sedangkan yang di maksud tradisional ialah segala apa yang diturunkan atau diwariskan secara turun temurun dari orang tua atau nenek moyang.

Permainan Tradisional adalah kekayaan budaya bangsa yang mempunyai nilai-nilai luhur agar dapat diwariskan kepada anak-anak sebagai generasi penerus. Permainan anak tradisional merupakan permainan yang mengandung wisdom (Suseno, 1999), memberikan manfaat untuk perkembangan anak (Iswinarti, 2005), merupakan kekayaan budaya bangsa (Sedyawati, 1999), dan refleksi budaya dan tumbuh kembang anak (Krisdyatmiko, 1999). 
Jadi permainan tradisional bisa diartikan sebagai kekayaan budaya bangsa yang mempunyai nilai-nilai luhur baik yang menggunakan alat atau tidak, yang diwariskan secara turun temurun dari nenek moyang sebagai sarana hiburan atau menyenangkan hati.

Berbagai macam permainan tradisional berkembang di provinsi Nusa Tenggara Barat, seperti Permainan Logok, Lunglungse, Manuk Kurung, Jumpring, Rabanga, Belanjakan, Presean, Mpaa Sila, Belonceq, Begasingan, Berapan Kebo, Karaci, Baleba, Parise, Menciwa, dan masih banyak lagi bermacam-macam permainan tradisional lainya. Seiring dengan perkembangan teknologi, sebagian besar anak-anak di jaman sekarang jarang, bahkan tidak lagi mengenal permainan tradisional tersebut, karena mereka lebih cenderung bermain game menggunakan alat-alat elektronik, misalnya Handphone, Ipad, Laptop, Komputer, Tablet, selain itu mereka juga lebih menyukai untuk bermain PlayStation hingga berjam-jam. Perkembangan teknologi dewasa ini mampu menghasilkan permainan modern seperti Mobile Legend, Heroes of 3 Kingdom, War 2, Angry Bird, PUBG dan permainan modern lainnya yang menyebabkan anak-anak Indonesia terutama anak-anak yang hidup di kota-kota besar mulai melupakan permainan tradisional warisan Indonesia khususnya permainan tradisional Nusa Tenggara Barat. Banyak pihak yang cenderung berargumen bahwa permainan tradisional sudah ketinggalan jaman. Padahal permainan tradisional memiliki banyak manfaat di dalamnya.

Berdasarkan persoalan di atas maka muncul masalah dimana permainan tradisional mulai menghilang dan anak bangsa Indonesia, khususnya Nusa tenggara Barat lebih menggemari permainan modern dengan menyebut dirinya sebagai anak gaul, sedangkan permainan tradisional dianggap permainan yang jadul (jaman dulu). Pemikiran ini menimbulkan kekhawatiran karena lambat laun permainan tradisional akan ditinggalkan dan tidak akan da yang melestarikannya. Anak-anak sebagai generasi penerus bangsa akan semakin terkungkung oleh permainan modern yang terdapat di handphone atau computer mereka. Fungsi motorik akan semakin jarang digunakan dan dilatih.

Penulis tertarik untuk mengkaji tentang memperkenalkan kembali macam-macam permainan tradisonal yang dimana permainan tradisional bukan permainan yang usang dan ketinggalan jaman.

\section{B. METODE PENELITIAN}

Pendekatan yang digunakan dalam penelitian ini adalah pendekatan kualitatif yang bersifat deskriptif. Sarwono, 2006 (dalam Laxmi, 2016) Pendekatan kualitatif adalah pendekatan yang menekankan pada makna, penalaran, definisi situasi tertentu, dan meneliti 
hal-hal yang berhubungan dengan kejadian sehari-hari. Menurut Arikunto, 2005 (dalam Laxmi, 2016) mengatakan penelitian desktiptif adalah penelitian yang menggambarkan apa adanya mengenai sesuatu variabel, gejala atau keadaan.

Dalam penelitian ini dikumpulkan dengan cara observasi, wawancara dan dokumentasi, yang dilakukan di masyarakat dan Museum NTB. Data penelitian adalah wujud dari data yang diperoleh meliputi bentuk bagaimana implementasi masyarakat dalam melestarikan permainan tradisional pada daerahnya msaing-masing. Teknik pengumpulan data adalah kegiatan yang sangat penting untuk memperoleh kejelasan dan kerincian data yang diterapkan dalam penelitian. Nazir, 1998 (dalam Laxmi, 2016). Teknik pengumpulan data juga merupakan prosedur yang sistematis dan standar untuk memperoleh data yang diperlukan. Teknik pengumpulan data dalam penelitian ini dilakukan dengan metode observasi, wawancara dan dokumentasi.

Nasution (Sugiyono, 2017) menyatakan bahwa dalam penelitian kualitatif, tidak ada pilihan lain daripada menjadikan manusia sebagai instrument penelitian utama. Alasannya ialah bahwa, segala sesuatunya belum mempunyai bentuk yang pasti. Masalah, focus penelitian, prosedur penelitian, hipotesis yang digunakan, bahkan hasil yang diharapkan, itu semuanya tidak dapat ditentukan secara pasti dan jelas sebelumnya. Segala sesuatu masih perlu dikembangkan sepanjang penelitian itu. Dalam keadaan yang serba tidak pasti dan tidak jelas itu, tidak ada pilihan lain dan hanya peneliti itu sendiri sebagai alat satu-satunya yang dapat mencapainya. Instrumen penelitian pada penelitian ini adalah peneliti sendiri, alat bantu yang digunakan adalah pedoman observasi, pedoman wawancara, dan pedoman dokumentasi.

\section{HASIL DAN PEMBAHASAN}

\section{Permainan Tradisional Pulau Lombok (Sasak) \\ a. Permainan Luglungse}

Permainan ini dikenal di seluruh daerah Lombok. Perbedaan sering terjadi pada syairsyair yang dibawakan. Lunglungse adalah nama lagu yang dinyanyikan. Permainan ini hampir sama dengan permainan mapoh-pohon di Bali, tetapi lebih panjang (ada tambahan). Permianan ini dimainkan secara berkelompok lebih dari 10 orang.

Sekelompok anak menunjuk dua orang yang lebih besar. Dua orang itu membuat terowongan (berhadapan dan kedua tangan bergandengan di keataskan) dan yang lain berderetan ke belakang pegang ikat pinggang di depannya. Mereka sambil menyanyi masuk terowongan. ekor barisan selalu ditangkap dan ditanya: ikut bulan atau bintang (lihat mopohpohon). Demikian berulang-ulang sampai seluruh anggota barisan tertangkap. Sampai di situ 
pada permainan mopoh-pohon berakhir, pemenang adalah yang mendapat anggota lebih banyak.

Pada permainan lunglungse dilanjutkan dengan tarik tangan antara kedua ketua (yang membentuk kedua terowongan tersebut) dibantu semua anggota masing0masing. Para pembantu menarik ikat pinggang teman didepannya. Yang kalah adalah tertarik lawan sampai melewati garis batas atau terjatuh. Garis itu disebut Gowet-wilayah. Ketua kelompok yang kalah dijadikan penjual bateq (penjual parang) anak buahnya bergabung kepada pemenang.

Selanjutnya dilakukan dialog antar penjual parang dan ketua yang menang. Materi dialog yaitu tawar-menawar harga parang dan ikan asin. Akhir pembicaraan, pedagang mengatakan ikan asin dimakan kucing. Permainan selanjutnya mencari kucing pemakan ikan asin. Semua pembeli (pemain) berbaris lurus dari depan ke belakang dengan kedua kaki terbuka lebar dan pedagang berada paling depan. Pedagang melempar parang ke belakang lewat selangkangan seluruh pemain. Siapa yang kakinya terkena parang, maka dialah kucingnya. Kemudian kucing dihukum menelungkupkan badannya.

Kemudian seluruh pemain menelentangkan tangan di atas punggung kucing urut melingkar. Sementara yang ditunjuk sebagai pemimpin memegang batu kecil dan ditekantekankan pada telapak tangan pemain secara urut diikuti nyanyian. Pada akhir nyanyian, batu ditaruh pada telapak tangan salah seorang dan digenggam. Seluruh pemain bersikap menggenggam pula. Kucing diminta menebak siapa yang menggenggam batu. Jika tidak bisa menebak, maka ia akan menelungkup lagi. Namun bila tebakannya benar, maka ia akan tergantikan oleh yang tertebak. Demikianlah sampai mereka puas.

b. Permainan Manuk Kurung

Manuk kurung berarti ayam kurungan. Permainan ini dilakukan oleh anak laki-laki umur 6-12 tahun. Sifat permainan adalah hiburan disaat luang (setelah membantu orang tua dilakukan di malam terang bulan.

Dalam sekelompok anak mencari pasangan masing-masing. Lalu mereka melakukan undian. Pemenang undian menjadi satu kelompok, demikian pula yang kalah. Masing-masing regu menunjuk ketuanya yang disebut pekembar. Kemudian setiap regu bersembunyi untuk memilih pemain yang berperan sebagai ayam. Setelah terpilih, lalu dikurung dengan sarung, kemudian kedua pekembar membawa ayam yang terkurung ke arena. Si ayam dalam kurungan mengelabui lawan dengan mengembangkan kain sarung lebih besar. Biasanya anak yang bentuk badannya diketahui oleh lawan tidak akan ditunjuk. Kedua pekembar berdialog sekitar ayam dari mana, keturunana berapa kali diadu, makanannya dan sebagainya. Selesai berdialog, maisng-masing disuruh berkokok. Baisanya ayam mengubah suaranya supaya tidak dikenal. 
Setelah berkokok, maisng-masing pekembar menebak siapa yang menajadi ayam. Jika tertebak, maka si ayam menajdi anggota regu penebak. Kalau tidak tertebak, masih tetap anggota regu asal. Jika kedua tebakan adalah tepat, maka terjadi seri atau maisng-masing kembali pada regunya. Permainan itu diulang sampai salah satu regu habis anggotanya atau kalah. Regu yang kalah harus menggendong pemenang pada jarak yang disepakati sebelumnya.

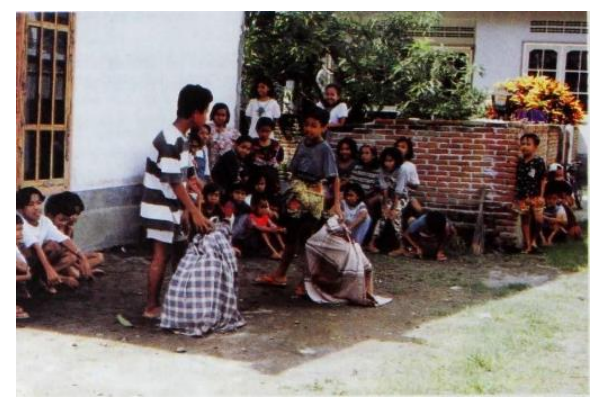

\section{Gambar 1. Permainan Manuk Kurung}

Permainan manuk kurung dapat membuat penonton tersenyum sebab yang dibungkus di dalam sarung bukan manuk tetapi manusia.

c. Permainan Peresean

Permianan ini sangat popular di kalangan suku Sasak di Lombok. Nama permainan diambil dari kata perisai atau tameng. Dahulu, permainan diselenggarakan saat upacara mohon hujan. Jika banyak darah mengucur dipandang hujan akan segera turun. Sekarang permainan telah memakai wasit yang disebut pekembar. Sebenarnya pekembar tidak sama dengan wasit, sebab pekembar dimiliki oleh kedua pemain artinya steiap pemain punya pekembar sendiri. Perelatan ende (perisai) dan penjalin (rotan) $\pm 1,5$ meter. Pemain laki-laki dewasa. Agar penjalin tidak mudah pecah, maka dipilih rotan tua dan ditengah dililit ijuk. Bahkan jaman dulu dilapisi timah diujungnya. Perisai dibuat dari kulit kambing dengan kerangka dan pegangan kayu, ukuran 1 x 0,75 meter. Pengiring gamelan peresean dan tiga macam gending (lagu):

- Gending pengalus, dimainkan saat mencari pemain atau metanding

- Gending pemapak, dimainlan untuk menyambut pemain yang telah setuju berain atau saat persiapan permainan.

- Gending pemangkep, dimainkan untuk mengiri permainan

Sebelum permainan dimulai gamelan peresean tersebut dibunyikan sebagai pengumuman mengundang penonton. Kemudian kedua pekembar mulai ngumbang atau menantang. Cara ngumbang yaitu ende diangkat memayungi kepala dan penjalin digerakgerakkan sambil menari yang disebut ngecak. Kedua pekembar yang ngumbang mendomenstrasikan peresean dengan memukul-mukul ende. Maksud ngumbang adalah 
merangsang calon pemain. Jika desa peserta banyak, maka mata angin tidak hanya empat, tetapi bisa sampai delapan. Setiap suku desa satu mata angin. Pemilihan lawan disebut nanding berdasarkan usia, besar kecil, ketenaran dan sebagainya. Apabila pemain membalik ende bisa punya arti tidak berani, bisa berarti minta lawan lainnya.

Setlah didapat yang cocok dan pakaian (seperti pakaian belanjakan) dan lain-lain siap, maka dilemparkan dua buah penjalin dan keduanya berebut. Sebelum ended an penjalin diangkat tidak boleh ada pihak memukul.

Kalau keduanya mengangkat ende dan penjalin barulah pertarungan dimulai. Pukul memukul terjadi diiringi gamelan disertai sorak penonton. Permainan terus ada kecuali ada yang cop. Alas an cop: pemain jatuh, alat lepas, pakaian lepas dan dihentikan oleh pekembar. Setelah ditarungkan, permainan istirahat dan dilanjutkan. Jika tidak ada yang kalah maka pekembar menyatakan sapih (seri). Penentuan pemenang sama dengan permainan belanjakan. Permainan peresean ini hamper sama teknisnya dengan permainan makare di Bali.

\section{Permainan Tradisional Sumbawa (Samawa)}

a. Permainan Logok

Logok adalah suatu jenis permainan tradisional dari daerah Sumbawa. Untuk permainan ini dibutuhkan logok yang terbuat dari tempurung kelapa berbentuk segi lima sebanyak 8-10 buah dan tongkat bamboo sepanjang $\pm 60 \mathrm{~cm}$.

Permainan logok dapat dilakukan secara perorangan atau berkelompok oleh laki-laki dewasa atau anak-anak. Logok dipasang di tanah dengan cara di tancamkan berjajar ke belakang, jarak logok yang satu dengan lainnya \pm 1 meter. Jarak logok dengan tabak (gacuk) \pm 10 meter. Para pemain dibagi dua yaitu pihak yang kalah dan yang menag. Pihak yang menang mengawali permainan. Dengan posisi badan membungkuk, kayu pemukul tegak lurus, tangan kiri menekan ujung kayu pemukul ke tanah, lalu tangan kanan memukul kayu agar mengenai tabak.

Apabila tabak menjatuhkan tiga buah logok, dan seterusnya disebut split, dan bila logok tidak dapat di jatuhkan sampai habis maka lawan dinyatakan kalah. Maka pemainnya diganti oleh lawan, demikian seterusnya. Apabila si pemain dapat menjatuhkan semua logok maka dinyatakan menang. Dalam permainan logok ada sanksi yang diterapkan sesuai dengan perjanjian atau kesepakatan kedua belah pihak.

\section{b. Permainan Rabanga}

Jenis permainan rabanga terdapat di daerah Sumbawa. Permainan rabanga dilakukan oleh laki-laki dua orang atau lebih. Terlebih dahulu pemain menyiapkan biji jambu mete 
sebanyak 10-30 biji. Disiapkan juga satu buah biji jambu mete yang tua lalu isinya dikeluarkan diganti dengan timah agar lebih berat. Biji mete ini dipakai sebagai tabak (gacuk).

Sebelum permainan di mulai terlebih dahulu dibuat lingkaran, dalam lingkaran itu dipasang biji jambu mete. Kira-kira jarak 1 hingga 2-meter dari lingkaran tersebut dibuat garis batas. Dari garis inilah para pemain mementil gacuknya agar mengenai biji jambu mete yang dipasang tadi. Jika si pemain bisa berhasil mengenai jambu mete yang dipasang itu serta mampu ke luar lingkaran maka ia dinyatakan menang. Bila yang terjadi sebaliknya maka ia dinyatakan kalah. Para pemain rabanga siap untuk melempar biji jambu mete yang disusun sejajar dalam suatu lingkaran.

c. Permainan Barapan Kebo

Berapan kebo atau kerapan kerbau di Sumbawa adalah sejenis kerapan sapi di Madura. Kerapan sapi diadakan di arena berupa tanah kering, sedangkan berapan kebo di arena berupa tanah atau sawah berlumpur yang digenangi air. Penyelenggara adalah baeng boat (pemilik sawah yang akan dijadikan arena). Baeng boat mengadakan pengumuman akan diadakannya berapan kebo di sawahnya kepada tentangga atau tetangga desa. Sawah yanf menjadi arena dibajak lebih dulu dan di airi \pm sebatas lutut. Mereka yang akan mengikuti berapan kebo menyiapkan kerbaunya dan meminta bantuan sanro atau dukun. Kerbau dari suatau desa bersama menuju tempat lomba diiringi saketa atau music Sumbawa. Di tempat lomba menunggu giliran di garis finish dipancangkan sakn (tonggak bentuk salip yang telah di mantrai oleh stuzro saka). Saka harus di langgar oleh pasangan kerbau yang mencapai finish. Saka dimantrai agar kerbau takut mendekat. Sebelum start, pasangan kerbau dibawa mengelilingi saka yang ngumang atau berkenalan. Ngumang diikuti balawan atau lagu daerah Sumbawa.

Setelah selesai ngumang, pasangan-pasangan kerbau itu di bawa ke belakang garis strat. Tau kareng telah siap dipasangan kerbau dabantu seorang pelepas. Setelah aba-aba diberikan, pasangan kerbau mulai berlari. Saat start, pelepas tadi masih maish ikut lari beberapa meter. Setelah kerbau berlari kencang, pelepas menyingkir ke pinggir arena. Tau kareng mengendalikan dan mengarahkan kerbau keraha saka. Sering terjadi keanehan, ekrbau yang dekat saka tiba-tiba berbelok arah. Kerbau yang menerjang saka berhak mengikuti ababk berikut. Dalam permainan ini dikenal semi final dan final. Kerbau yang menang mendapatkan hadiah tertinggi berupa kerbau dan pemenang itu akan naik harga kerbaunya.

d. Permainan Karaci

Permainan ini terdapat di Sumbawa. Karaci berarti memukul bertubi-tubi. Alat pemukulnya disebut karaci. Dahulu dalam jaman Kesultanan Sumbawa terdapat kelompok 
Juram Empar atau penduduk asli dan kelompok Marisi atau pendatang. Dalam upacara istana banyak persembahan: kelompok Bugis-tari setnpa, kelompok Bajo-tari joge, masyarakat Moya Hilir-permainan karaci.

Teknik dan peraturan permainan karaci sama dengan permainan peresean di Lombok. Alat permainan juga sama yaitu rotan pemukul dan perisai, maka dalam uraian ini cukup diberikan perbedaan istilah dan jenisnya.

Pekembar di peresean disebut kepala di karaci. Ende di peresean disebut empar di karaci. Penjalin di peresean disebut we di karaci. Dalam permainan karaci, pemain menggunakan pabulang yaitu penutup kepala dan badan. Pabulang dibuat dari kain berlapis kapuk sampai tebal, selain itu terdapat Tau besengkela yaitu pemisah semacam wasit. Cara memisah dengan memalangkan galah diantara kedua pemain. Dalam permainan karaci tidak terdapat kalah atau menang.

\section{Permainan Tradisional Mbojo}

a. Permainan Mpaa Sila

Mpaa sila berarti permainan silat di derah Bima dan Dompu. Permainan dilakukan oleh dua orang laki-laki dewasa. Pada masa lalu Mpaa sila merupakan permainan rakyat yang dipersembahkan kepada Sultan Bima ketika berlangsung upacara adat. Sekarang Mpaa Sila merupakan permainan rakyat untuk menghibur masyarakat.

Pada permainan Mpaa Sila, masing-masing pemain dengan oedang di tangan menunjukkan ketangkasan bermain silat dan bermain pedang. Sambil bergerak kesana kemari, berkeliling, sebagaimana layaknya orang menari. Ketika itu seorang pemain mengintai dan merancang strategi untuk mengenai lawannya sedangkanseorang lagi mengantisipasi agar tidak kena tebasan pedang lawan atau sapuan kaki lawan.

Dalam permainan ini, tidak ada yang kalah atau menang. Didalam permainan dan lama permainan tidak ditentukan. Adakalanya permainan ini memakai musik pengiring tetapi ada juga yang tanpa musik pengiring. Dalam pertandingan Mpaa Sila, pemain harus dapat menunjukkan ketangkasan bermain silat dan pedang.

b. Permainan Baleba

Permainan Baleba dilakukan oleh dua ofrang laki-laki dewasa atau orang tua di daerah Dompu. Alat pendukung permainan ini adalah 2 potong kayu panjang $30 \mathrm{~cm}$. permainan ini memakai music pengiring yaitu dua buah gendang dan masing-masing permainan memegang tongkat.

Permainan diawali oleh salah seorang pemain. Ia melakukan gerakan pembukaan yang diakhiri dengan sikap hormat kepada penonton kemudian lawannya bermain juga melakukan 
gerakan yang sama. Selanjutnya kedua pemain sama-sama memasuki arena untuk saling menghormat dengan sikap saling menundukkan kepala, setelah itu barulah mereka saling memukul. Masing-maisng pemain berusaha agar pukulannya mengenai tubuh lawan.

Permainan ini semakin seru apabila bunyi gendang pengiring bertambah keras sampai akhirnya permainan dinyatakan berhenti apabila salah seorang pemain memberikan kode bahwa dia sudah tidak mampu lagi melanjutkan permainan. untuk selanjutnya diganti dengan pemain lain. Biasanya permainan ini dilaksanakan pada upacara kegiatan adat seperti khitanan, perkawinan dan acara keramaian lainnya.

\section{SIMPULAN}

Berdasarkan hasil penelitian dan pembahasan diatas maka disimpulkan bahwa terdapat banyak sekali permainan tradisional yang ada di provinsi Nusa Tenggara Barat (NTB) sesuai dengan daerah dan suku masing-masing, diantaranya adalah untuk permainan tradisional suku sasak yaitu Permainan Lunglungse, Permainan Manuk Kurung, Perminan Jumpring, Permainan Belanjakan dan Permainan Peresean. Permainan tradisional suku samawa (Sumbawa) yaitu Permainan Logok, Permainan Rabanga, Permianan Berapan Kebo dan Permainan Karaci. Permainan tradisional suku Mbojo yaitu Permainan Mpaa Sila, dan Permainan Baleba.

\section{DAFTAR PUSTAKA}

Iswinarti. 2005. Identifikasi permainan tradisional Indonesia. Laporan hasil survey. Malang: Fakultas Psikologi UMM

Krisdyatmiko. 1999. Dolanan anak: Refleksi budaya dan wahana tumbuhkembanganak. Yogyakarta: Plan International Indonesia-Yogyakarta dan LPM Sosiatri Fisipol UGM

Laxmi. 2016. Pelaksanaan Ekstrakulikelur Berbasis Kearifan Lokal Di SMAN 8 Mataram, Nusa Tanggara Barat (NTB). Mataram: Departemen Pendidikan dan Kebudayaan Kantor Wilayah Provinsi Nusa Tenggara Barat.

Moleong, Lexy J. 2005. Metodologi Penelitian Kualitatif(Edisi Revisi). Bandung: PT Remaja Rosdakarya.

Sedyawati, E. 1999. Permainan Anak-anak sebagai Aspek Budaya. Yogyakarta: Plan International Indonesia-Yogyakarta dan LPM Sosiatri Fisipol UGM.

Sugiyono. 2017. Metode Penelitian Pendidikan.Bandung: Alfabeta. 